\title{
荷兰工业遗产保护与再利用概述
}

\section{The Overview of the Conservation and Reuse of Industrial Heritage in the Netherlands}

摘要: 荷兰不仅在当代建筑创作领域中走在 世界前列，在城市更新特别是工业遗产保护与 再利用方面也有相当丰富的经验。近年来, 荷 兰在实现城市更新的过程中涌现出诸多充满 创造力的工业遗产再利用项目。本文介绍了荷 兰工业遗产的基本内容及其保护与再利用的 整体情况，分析并提炼了其工业遗产保护与再 利用的若干思路和经验, 以期为我国工业遗产 保护和城市复兴提供参考和借鉴。

Abstract: Not only does the Netherlands play a leading role in the modern architecture design, but also gain a wealthy practice and experience of reusing the old industrial buildings actually. A number of successful projects have been carried out in the Netherlands nowadays. The paper intends to introduce the overall situation of the industrial buildings reuse and conservation in the Netherlands, which aiming at analyzing and refining the ideas of its experience.

关键词：工业遗产; 保护; 再利用; 城市更新; 荷兰

Keywords: Industrial heritage; Conservation; Reuse; Urban Regeneration; The Netherlands

作者: 孟璠磊, 清华大学建筑学院、荷兰代 尔夫特理工大学联合培养博士研究生。 mf113@mails.tsinghua.edu.cn

\section{1 荷兰工业遗产概况}

\section{1 工业发展概述}

19 世纪中期以前, 荷兰一直是欧洲的传统农业国家, 农民主要依靠农作物 种植、牛奶制品加工等产业自给自足 ${ }^{[1]}$ 。虽与英国隔海相望, 但工业革命在荷兰 传播得并不迅速, 特别是传统手工业面对蒸汽机有着强烈的抵触和排斥情绪。直 到 1870 年后, 荷兰才开始逐步使用蒸汽机来代替传统机械, 代表事件是哈勒姆 (Haarlem) 地区的填海造陆工程 ${ }^{[2]}$ —驱动排水的不再是传统的荷兰风车, 而是 来自英国康沃尔 (Cornwall) 钢铁公司的蒸汽机。

此后, 荷兰工业迅速发展, 特别是港口的物流运输业, 阿姆斯特丹港和鹿特 丹港逐渐成为荷兰乃至西欧最重要的物流枢纽。与此同时, 一些新型加工制造业 也开始在荷兰境内涌现, 诞生了一系列享誉世界的企业, 如飞利浦 (Philips) 电 器制造厂、喜力 (Heineken) 啤酒厂等。

\section{2 考察与记录}

虽然英国的工业革命进人荷兰用了近一个世纪的时间，但荷兰开展工业遗产 考察却紧随英国工业考古之后。1970 年, 荷兰开始着手本国工业遗产考察工作 ${ }^{[3]}$, 工厂历史研究小组（WB: Werkgroep Bedrijfsgeschiedenies）主要负责工业史的研究, 技术历史研究小组（WGT: Werkgroep Geschiedenis van de Techeniek）则主要负责 工业技术的研究。其中代表人物是历史学和产业学领域的专家彼得. 尼霍夫 (Peter Nijhof), 他用了近 20 年时间, 对荷兰境内的工业遗产进行了深人的走访和调研, 并出版了大量研究成果, 包括一些主要城市如阿姆斯特丹 (Amsteredam)、鹿特 丹 (Rotterdam)、乌得勒支 (Utrecht)、埃因霍温（Eindhoven）的工业遗产现状 及历史等。

1984 年, 荷兰多个地方性考古团体共同成立 “荷兰工业遗产联合会”（FIEN： Federatie Industrieel Erfgoed Nederland)，这是欧洲第一个直接以 “工业遗产” 而非 “工业考古” 命名的机构（除“国际工业遗产保护委员会” [TICCIH] 外）（表 1)。

而在工业遗产的档案记录方面, 荷兰建立了自己的一套标准 : 除沿用英国 AIA 工业遗产调查手册中的表格 ${ }^{[4]}$ 和遗产价值评估表格外, 还有一组专门针对工 业遗存再利用的 “项目发展” 表格, 用于描述和记录该工业项目是否会进行再利 
用 ${ }^{[5]}$ 。如图 1 所示, 除了要求对考察对象进行正面记录外, 还包括负面或消极评价, 以使档案客观和全面。

\section{2 荷兰工业遗产}

\section{1 主要类型}

荷兰历史学界一般将 1870 年代作为荷兰近现代工业发 展的开端，在此之前的工业遗迹被称为 “早期传统工业遗

\begin{tabular}{|c|c|c|c|c|}
\hline 项目名称 & \multicolumn{2}{|l|}{ 区位 } & \multicolumn{2}{|l|}{\begin{tabular}{|l|} 
日期 \\
拍摄日期
\end{tabular}} \\
\hline \multicolumn{5}{|l|}{ 描述说明 } \\
\hline \multirow{3}{*}{$\begin{array}{l}\text { 更多信息 } \\
\text { 作者 } \\
\text { 状态 } \\
\text { 格式 } \\
\text { 收藏处 } \\
\text { 来源地 } \\
\text { 版权 / 再版 }\end{array}$} & \multicolumn{2}{|c|}{ 积极的 } & \multicolumn{2}{|c|}{ 消极的 } \\
\hline & 原件 & 复印件 & 原件 & 复印件 \\
\hline & & & & \\
\hline
\end{tabular}

历史记载

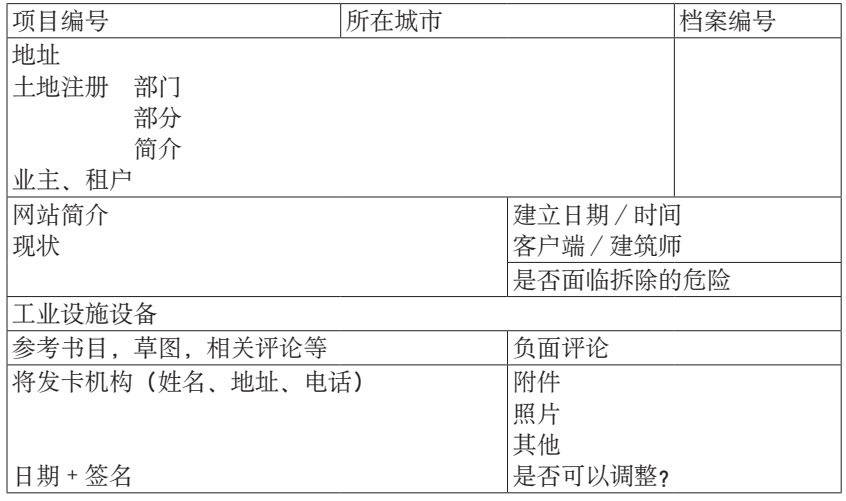

图 1 荷兰工业遗产考察记录 “项目发展” 表格 资料来源: 作者根据参考文献 [5] 翻译绘制
产”, 主要代表是与灌溉和动能密切相关的工业设施一风 车。荷兰是低地国家, 人们需要克服生活用地低于海平面的 环境。早期发展农业时, 人们利用木材制造风车的扇叶和齿 轮, 将风能转换为动能, 将低地水抽到更高的位置, 以确保 生活用地干燥坚固。收藏在阿姆斯特丹荷兰国家美术馆（Rijk Museum) 的画作 “河边的风车” (Molen bij een rivier) ${ }^{[6]}$, 由画家菲斯海尔 (Claes Jansz. Visscher) 于 1613 年创作, 是 目前最早的专门反映风车的钢笔画作品（图 2)。这一时期 其他类型的工业遗产还包括水塔、沟渠以及建在港口周边的 小型手工纺织厂、酿造厂等。

英国工业革命 20 年后 (1870 年代), 欧洲工业产品的 制造效率大幅度提升, 与之对应的贸易往来也与日俱增。到 19 世纪末期, 荷兰集中出现了大量的啤酒酿造厂、大型桥

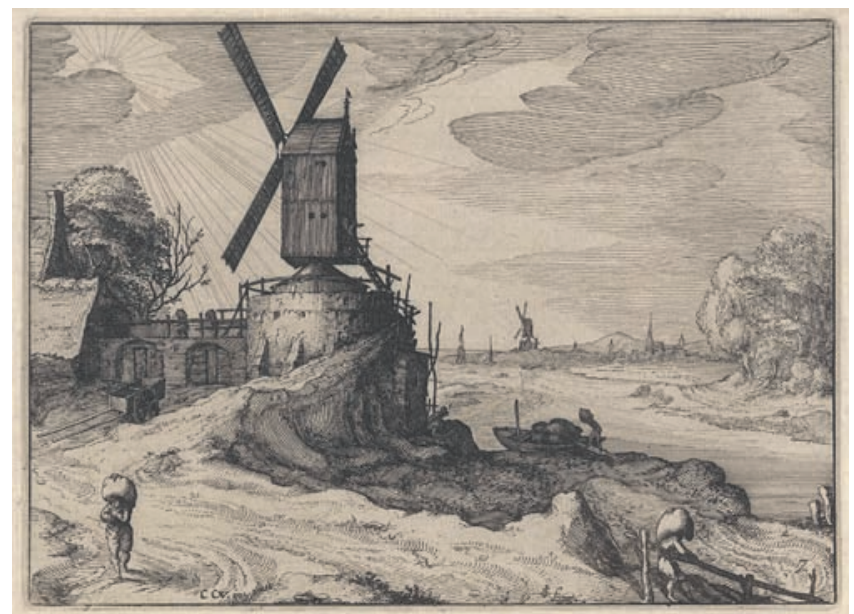

图 2 河边的风车, 1613 年

资料来源 : 荷兰国家博物馆 (Rijk Museum) 公开图片资料

\section{表 1 欧洲部分国家工业遗产考察及研究机构的成立时间表}

\begin{tabular}{|c|c|c|c|c|c|}
\hline 序号 & 国家 & 组织机构 & 简称 & 组织机构全称 & 成立时间 \\
\hline 1 & 英国 & 工业考古联合会 & AIA & Association for Industrial Archaeology & 1973 \\
\hline 2 & 德国 & 国际工业遗产保护委员会德国分会 & TICCIH Deutsch & TICCIH Deutsch & 1978 \\
\hline 3 & 法国 & 工业考古及遗产学习联合会 & CILAC & $\begin{array}{l}\text { Comité d'information et de liaison pour l'archéologie, l'étude et la } \\
\text { mise en valeur du patrimoine industriel }\end{array}$ & 1979 \\
\hline 4 & 丹麦 & 工业环境保护公司 & SBI & Selskabet til Bevaring af Industrimiljøer & 1979 \\
\hline 5 & 荷兰 & 荷兰工业遗产联合会 & FIEN & Federatie Industrieel Erfgoed Nederland & 1984 \\
\hline 6 & 比利时 & 瓦隆一布鲁塞尔工业遗产联合会 & PIWB & Patrimoine Industriel Wallonie-Bruxelles & 1984 \\
\hline 7 & 瑞典 & 瑞典工业联合会 & SIM & Svenska industriminnesföreningen & 1989 \\
\hline 8 & 希腊 & 国际工业遗产保护委员会希腊分会 & TICCIH Greece & TICCIH Greek Section & 1992 \\
\hline 9 & 瑞士 & $\begin{array}{l}\text { 瑞士工业遗产与技术历史联合会（由前 ETH } \\
\text { 技术考古小组和技术历史联合会合并而来） }\end{array}$ & SGTI & Schweizerische Gesellschaft für Technikgeschichte und Industriekultur & 1996 \\
\hline 10 & 爱尔兰 & 爱尔兰工业遗产联合会 & IHAI & Industrial Heritage Association of Ireland & 1996 \\
\hline 11 & 意大利 & 意大利工业考古及遗产联合会 & AIPAI & L'Associazione Italiana per il Patrimonio Archeologico Industriale & 1997 \\
\hline 12 & 葡萄牙 & 葡萄牙工业遗产联合会 & APPI & Associação Portuguesa para o Património Industrial & 1997 \\
\hline 13 & 西班牙 & 国际工业遗产保护委员会西班牙分会 & TICCIH España & TICCIH España & 1999 \\
\hline
\end{tabular}

资料来源：作者整理绘制 
梁甚至铁路转运站等。但这段时期的大规模扩张使工业建筑 的设计及建造并未经过太多认真的思考和推敲, 几乎没有人 去研究这些建构筑物应该使用什么材料, 以及采取什么形式。 因此, 这一时期的工业建筑在形态上与一般民用建筑并无明 显区别 ${ }^{[7]}$, 如建于 19 世纪末期的斯希丹酿酒厂 (Schiedam), 建筑造型与当时荷兰民居十分接近 (图 3)。一些水站、水 塔建造得如同中世纪的城堡, 如 1896 年建于乌得勒支的水 塔 ${ }^{[8]}$, 目前已经改造为博物馆 (图 4)。

20 世纪上半叶, 两次世界大战爆发, 客观上推动了荷 兰工业的快速发展。与荷兰东部毗邻的德国鲁尔区是欧洲的 煤矿和钢铁基地, 产品经荷兰境内发达的运河网络运往西欧 各国, 曾经是渔港的鹿特丹由此逐渐发展成荷兰乃至欧洲地 区的海运物流枢纽 ${ }^{[9]}$, 由此兴建了相当数量的港口工业建筑, 包括仓库、桥梁等 (图 5)。此后, 荷兰工业建筑受到国际 化的广泛影响, 开始尝试使用新型建筑材料, 包括预应力钢 筋混凝土和钢铁、玻璃等, 工业建筑的风格和材料的运用等 开始与世界接轨。

\section{2 主要特点}

荷兰国土面积较小且工业起步较晚, 因此工业遗产在很 多方面都不能与传统工业强国相提并论：从时间跨度上不及 英国的古老久远, 从占地规模上不及德国的宏大壮观, 而从 工业门类上也不及美国的完整齐备, 但它们却依然有着自身 突出的地域性。

风车为荷兰的古代和近代生产生活提供了重要的动力来 源, 是荷兰工业遗产的代表。19 世纪中期, 荷兰曾有近万 座不同类型风车, 虽然今天仅剩下不到 1000 座 ${ }^{[10]}$, 但这些 风车在荷兰不断演变和进化: 造型上从最初独立的构筑物发 展成后期与住屋相结合, 建筑材料上从早期的木板到后来的 砖与钢构架结合等。在这些保存下来的风车中, 一部分仍继 续工作, 另一部分则被打造成旅游景点, 每年吸引数百万游 客前来参观。如位于阿姆斯特丹的 Zaanse Schans 风车群、位
于鹿特丹的 Kinderdijk 风车群、De Ster and De Lelie 风车群等。 其中, Kinderdijk 风车群在 1997 年被列为世界文化遗产, 也 成为荷兰的国家象征。

此外, 荷兰国土面积有限, 但却拥有两座世界级港口： 阿姆斯特丹港和鹿特丹港, 它们今天依然侪身欧洲最活跃的 物流枢纽之列。一系列围绕港口物流兴建的仓库、车间、码 头等设施设备成为荷兰现代工业遗产的主体, 如阿姆斯特丹 船厂艺术区 (NDSM)、阿姆斯特丹东港区 (Eastern Dock)、 鹿特丹的 Leuvehaven 码头等等, 它们是数量最多的工业遗产 类型, 见证了荷兰近代工业的启蒙、发展和壮大。

\section{3 荷兰工业遗产的保护与再利用}

\section{1 整体式的稳态保存}

在风车的保存和再利用中, 一些历史价值较高的风车被 改造成体验式博物馆向公众开放。除了风车单体外, 辅助风 车运行的一些功能性房间及其环境也均得到保留（图 6), 包 括火炉间、储藏间、河道、芦苇以及原生态的景观等, 以保 证风车遗产的整体性和原真性, 使其保持在一个稳定的环境 下不被过分现代化。例如, Kindedijk 风车群遗产不仅包括风 车本身, 还包括 “上瓦尔德区” (Overwarrd)、“下瓦尔德区”

(Nederwaard)、“新莱克兰德 (Nieuw-Lekkerland) 新生地”、 “布劳克威尔（Blokweer）新生地” 四处圩田和附属建筑物 等, 它们保护的不仅仅是风车个体, 还有周边一体化的生产 景观。

博物馆门票的收人用来保证风车的维护和当地住民的生 活, 住民被政府号召起来成为导游, 向游客解释风车的机械 原理和古代人们生产生活的历史（图 7)。风车内部的原始 构件及生活空间也都完好并清晰地展现了出来（图 8, 图 9)。

\section{2 选择性的动态更新}

港口工业遗产由于占地庞大、历史短暂且缺乏装饰, 导 致民众也曾对它们产生排斥的情绪。但工业考古的理念使人

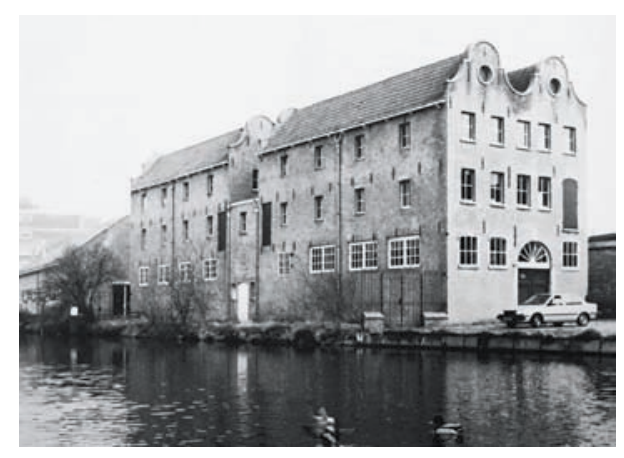

图 3 建于 19 世纪末期的斯希丹酿酒厂历史照片 资料来源 : 参考文献 [7]

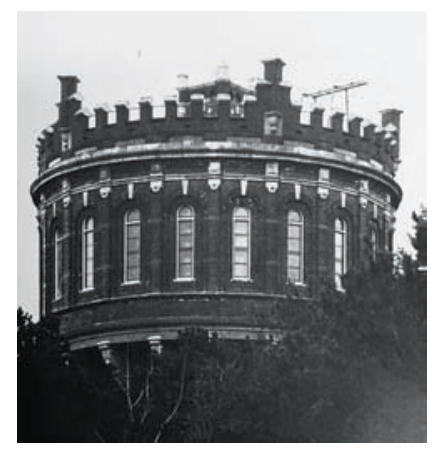

图 4 建于 1896 年的乌得勒支水塔 资料来源 : 同图 3

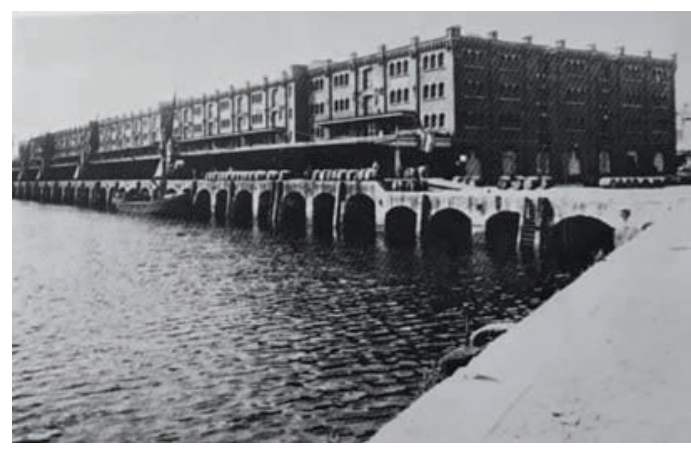

图 5 鹿特丹港口仓库历史照片 资料来源 : 参考文献 [8] 
们逐渐意识到, 一个 19 世纪的工厂对人们的影响甚至超过 一座中世纪的教堂, 因为这些工厂为推动社会的发展和经济 的繁荣起到了重要的作用。与其拆除这些仓库, 不如对它们 进行改造再利用, 这样既保留住工业发展的印记, 又使其继 续为现代生活服务。在这些数量庞大的工业遗存之中, 荷兰 人有选择性地进行改造和逐步更新。除了常见的将之转换为 办公、住宅或商业空间外, 还不乏一些富有挑战性的大胆尝 试，大批旧仓库、码头、厂房以及工业设施设备等成为荷兰 建筑师发挥创造力的实验田。

例如, 位于阿姆斯特丹运河北部 NDSM 艺术区的天车 酒店（Faralda Crane Hotel）就是一个不断更新和变化的工业 遗产再利用项目。该项目中原有的起重天车因弃用而年久失 修, 但因被艺术家当作涂鸦艺术场所而得以保留。当人们对 这座天车的认识还停留在一座工业地标物的层面上, 来自荷 兰的建筑事务所 SID Studio 却提出了一个大胆的想法 : 将港 口装卸货物的起重天车顶部进行建筑化改造, 在其 $50 \mathrm{~m}$ 的 高度植人三个集装箱式舱体, 改造为体验式酒店。巨大的天 车在 2013 年 7 月被拆解成不同的组块, 运往工厂进行建筑 化改造, 重新加固、涂装, 半年后全部完工并运到原地进 行重组（图 10一图 12）故造后的酒店得到了广泛好评, 吸引了无数的游客前来体验, 在 2015 年同时获得了欧洲的
三项酒店大奖 : 服务业创新奖、最佳技术应用奖, 年度明星 酒店。

再如, 位于阿姆斯特丹城市中心区的原煤气厂, 倒闭 后城为城市中心的一处 “疾患”, 但在荷兰推进工业旧建筑 更新的过程中, 这里被打造成了一座开放的城市休闲公园 （图 13）。旧工业建筑改造成商业集市（图 14, 图 15), 煤 气厂则被改成剧场, 定期举办演出或者发布会, 有效恢复了 当地活力, 甚至吸引了其他地区居民前来此地, 是修复工业 遗产地段区的一次有益尝试。又如鹿特丹一座建于 16 世纪 的码头 Leuvehaven, 由于规模无法满足现代停靠需要而逐渐 废弃, 但工业设施和构筑物被保留下来, 结合其场地改造成 了 “鹿特丹海事博物馆”, 并在沿街面置人小规模商业以维 持老码头的人气, 使之成为一条休闲的生活街道, 现在已经 成为鹿特丹城市旅游中的重要针点（图 16）。

\section{4 启示与结语}

荷兰在过去的 10 多年时间里, 一直致力于工业遗产的 保护和再利用。荷兰工业遗产与其他传统遗产最主要的区 别在于突出其再利用的价值, 即以“再利用” 的手段达到 “保护” 的目的。在被列人 “国家级不可移动类的纪念物” (Rijksmonument) 的 “工业遗产” (Industrieel erfgoed) 中,

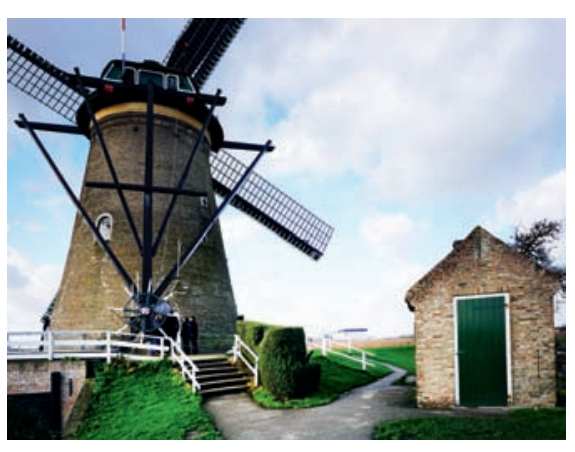

图 6 风车与附属建筑共存

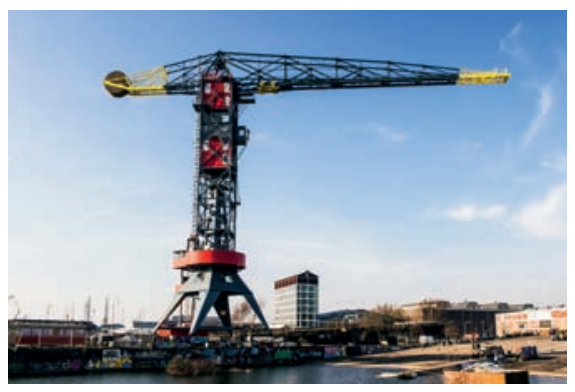

图 10 天车改造成酒店后实景

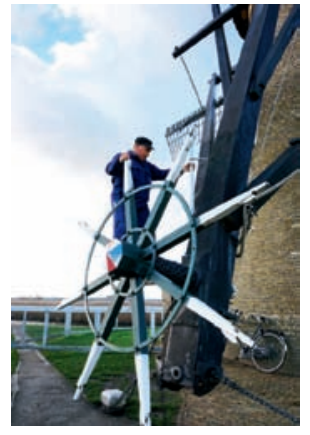

图 7 原住民操作风车向 游客展示

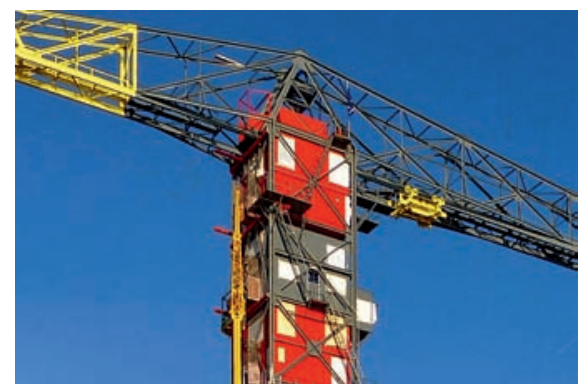

图 11 三个酒店套房

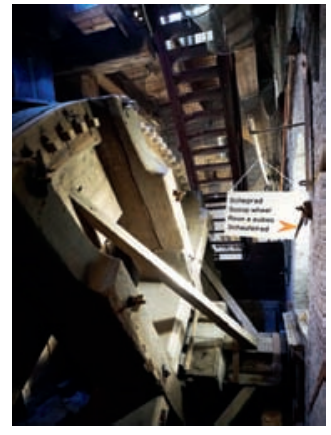

图 8 风车内部保存完好的 木质机械部件

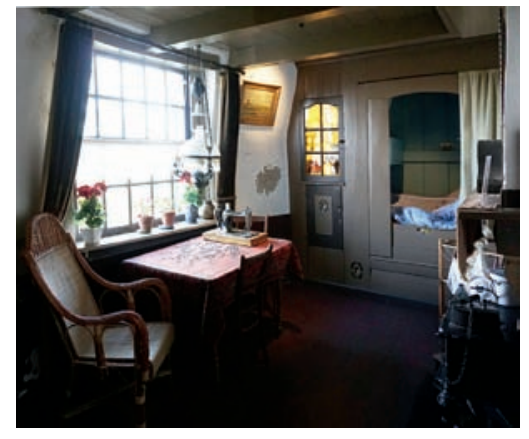

图 9 风车内部生活房间

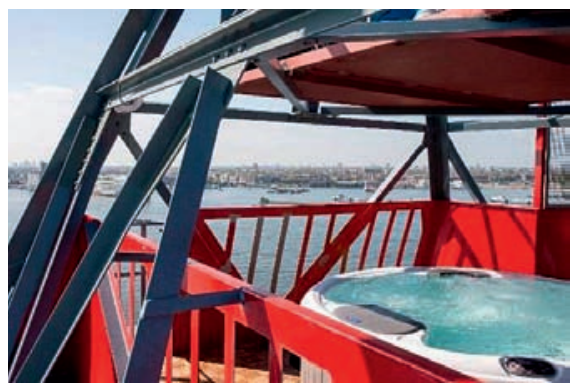

图 12 露天泳池

资料来源 : http://www.iamsterdam.com

(1) http://www.faralda.nl/ 
依据类型和价值的不同, 被重新加以利用。如, 位于埃因霍 温的原飞利浦灯泡公司, 是享誉世界的电器制造厂, 在飞 利浦工厂搬迁至阿姆斯特丹后原有厂房被废弃, 其中有 10 余处工业建筑物或构筑物被列为 “国家级不可移动类纪念 物”, 其中灯泡车间由于建造年代最早, 且历史价值突出而 被改造成飞利浦工业遗产博物馆（图 17, 图 18); 安东大楼 由于是第一批包豪斯风格的多层厂房且建筑质量较好, 而被 改造成文化创意办公区和 Loft 居住区等等（图 19)。这些工 业建筑遗产的保护不是简单的改造成 “展品”, 而是被赋予 了新的功能, 容纳新的使用人群和活动内容, 反映出不同价 值、不同类型的工业遗产在保护再利用过程中的适应性和 差异性。

而除了建筑单体改造外, 荷兰还创造了一批推动地区复 兴的大型项目, 如以艺术家聚集区为转型目标的原阿姆斯特
丹造船厂改造—NDSM 艺术区（图 20), 以多功能混合居 住为转型目标的东港码头区改造一一原阿姆斯特丹 KNSM 码 头（图 21）等等, 它们为当代荷兰城市发展提供了新的动力, 成为城市复兴新引擎。

如果说英国和德国是欧洲工业遗产保护的领导者, 那么 荷兰则可以称得上是通过工业遗产的再利用来实现城市复兴 的 “生力军”。从荷兰的经验来看, 工业遗产不仅没有成为 城市发展的负担, 反而成为人们创意生活的舞台。荷兰建筑 师不断研究和探索工业遗产在当下社会发展中的出路, 没有 单纯将之看作孤立的历史遗迹, 反而努力使它们融人现代生 活, 这一思路值得我们借鉴。

注: 文中未注明资料来源的图片均为作者拍摄。

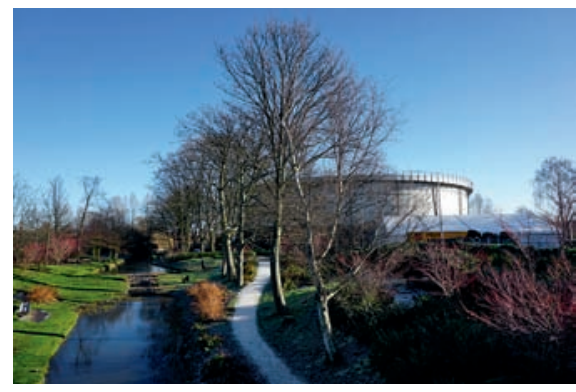

图 13 煤气厂改造成城市开放公园

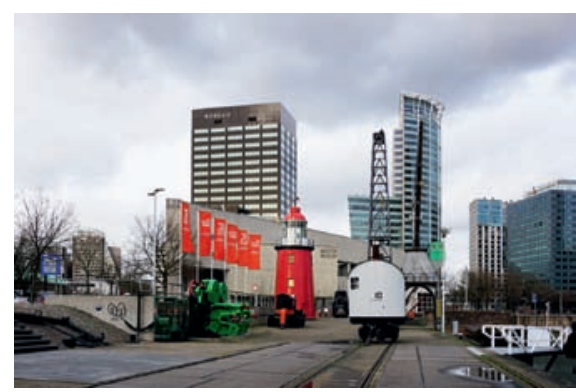

图 16 鹿特丹 Leuvehaven 码头保留的铁轨和 设备

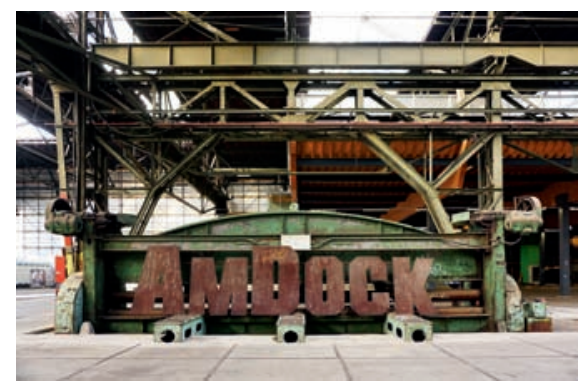

图 19 埃因霍温安东大楼改造成文化创意产业 园区

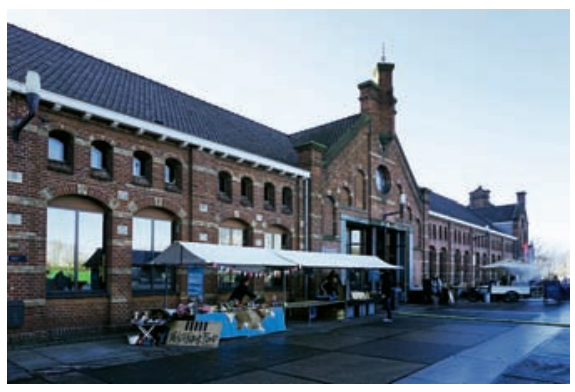

图 14 煤气厂办公楼改造成集市

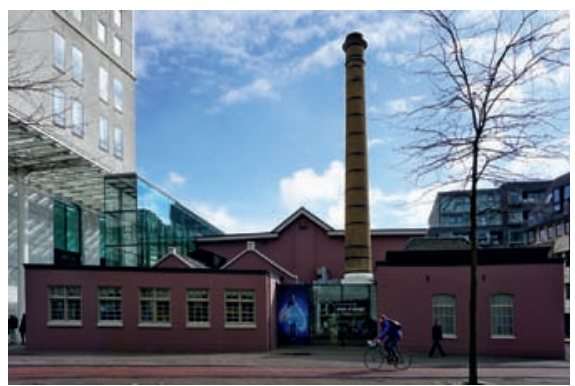

图 17 埃因霍温飞利浦工业遗产博物馆

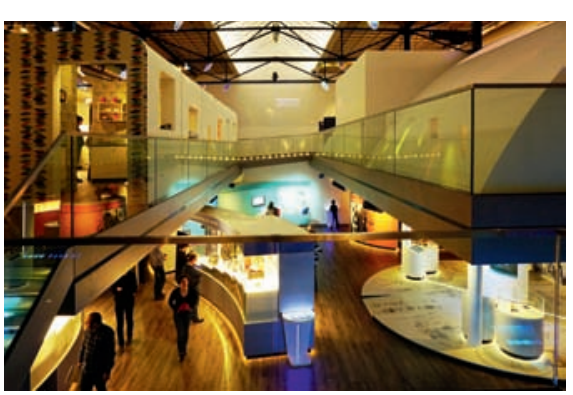

图 20 阿姆斯特丹 NDSM 艺术区实景

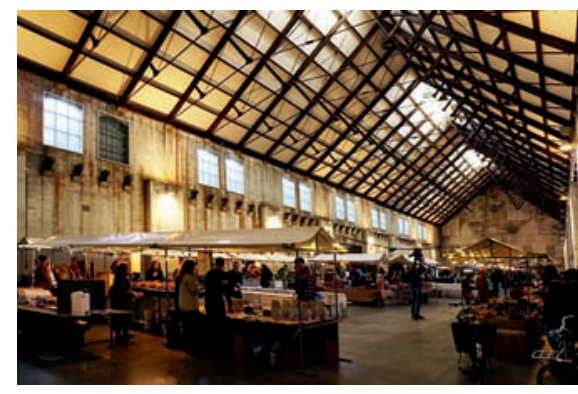

图 15 办公楼改造后内部

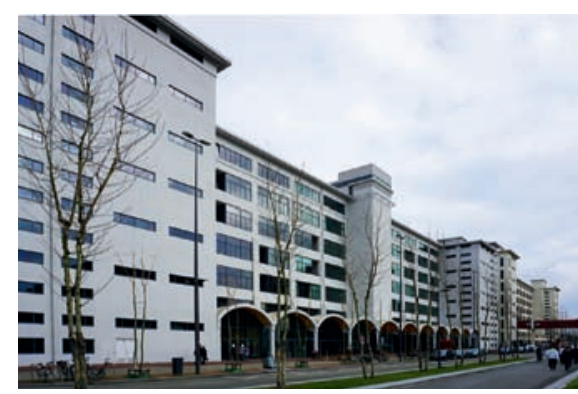

图 18 埃因霍温飞利浦工业遗产博物馆内景

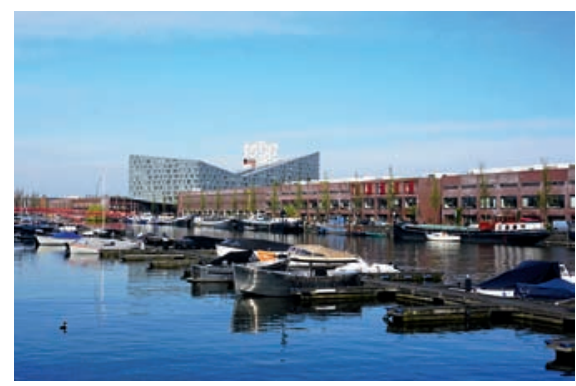

图 21 阿姆斯特丹东港码头居住区实景 


\section{参考文献}

[1] Hudson Kenneth. A Guide to the Industrial Archaeology of Europe[M]. Bath: Adams and Dart, 1971.

[2] Hoeksema Robert J. Three Stages in the History of Land Reclamation in the Netherlands[J]. Irrigation and Drainage v56 nS1, 2007(12): S113-S126.

[3] Nijhof Peter, Zoetendaal Willem van, Zilvold Rien. Industriele Monumenten[M]. Amsterdam: Fragment, 1989.

[4] Williams Julie . Recording the Industrial Heritage: Index Record for Industrial Sites[M]. Lindon: Association for Industrial Achaeology, 1993.

[5] Kappelhof Ton, Nederlandse Jeugdbond ter Bestudering van de Geschiedenis. Industriele archeologie: een terreinverkenning[M]. Gorinchem: Mandarijn, 1981.
[6] Rosenberg Jakob. Dutch Art and Architecture: 1600 to $1800[\mathrm{M}]$. Harmondsworth, etc.: Penguin Books, 1966.

[7] Nijhof Peter. Oude fabrieksgebouwen in Nederland[M]. Amsterdam, etc.: De Bataafsche Leeuw, 1985.

[8] Henk van der Veen. Watertorens in Nederland[M]. Rotterdam: Uitgeverij 010, cop., 1989

[9] Jurr A van Dalen. Oud Werk: overzicht van industrieel erfgoed in Rotterdam[M]. Rotterdam: Stichting Industrieel Erfgoed Rijnmond, 1983.

[10] Nijhof Peter. Windmolens in Nederland[M]. Zwolle: Waanders, 1983.

(本文编辑：王枫)

(上接 100 页)

宜居城市的任意两个地区的形态不会完全一样。即使在 无地形地貌突出特征的平原地区, 同样有平原独特的自然美, 当然, 那里的土地使用模式可能会重复, 那里都有农田和森 林。我们设想要建设的新型城市一定是顺其自然的城市, 寻 求与建成环境相伴的景观美, 而不那么寻求建筑在自然环境 之上的建筑美, 也就是说, 开发是顺从自然景观特征的, 而 不再把建筑物搁在自然景观上。这样, 顺其自然的城市必然 会出现不计其数的有差别的城市单元，从而突显地方特征。 多种地形地貌保留了下来, 便会产生地域和个性自然地结合 在一起的景观效果。所有的建设都会自然地找到自然的表达。

宜居城市不再划分出细小的土地使用功能分区。在宜居 城市的建设过程中, 不再使用生产工具去蓄意破坏自然美, 去为了自己的蝇头小利而不断地破坏自然环境。所谓“服务 设施” (电线杆子、电线、电话线, 围墙) 对自然景观的破坏, 沿着道路一字排开的不良商业广告, 都会一起消失掉。人们 会正常生活, 不再有机器的呼啸、抽泣、轰鸣! 不再面临持 续不断的危险。现在的很多事情都不应该再发生了。

宜居城市不再划分主轴和次轴, 顺其自然, 让平面自由; 宜居城市的空间间隔是用时间来计算的，这种以时间尺度衡 量的新的标准空间间隔会对每一规划元素产生重大影响, 这 些影响会出现在每一幢建筑中。

宜居城市不再时兴“风格”, 风格随处绽放, 而随处绽 放的风格都是顺其自然的。

宜居城市的空气、饮水、食品都是新鲜的, 头上是明媚 的阳光, 脚下是绿色的土地, 现代家用设备还会在家庭生活 中持续存在下去。现代的钢铁、玻璃和塑料自然会按照它们 的属性而被合理地利用起来。
宜居城市就在我们每个人的家里, 我们的居住空间里, 因为建筑内部的居住空间就是实际的建筑空间, 我们每个人都 成了宜居城市的建设者, 所以, 以时间尺度衡量的新的空间概 念不仅仅用于建筑本身, 而且用到人本身的思维和行动上。

宜居城市本身就是一幢有生命的建筑。它的道路系统、 建筑物、花园、工厂和田野, 分别是那个城市的动脉和静脉、 细胞组织、笑容, 养料和活力之源, 有机地结合一起。

宜居城市在发展现代文明的同时延续了我们历史文明, 所以, 宜居城市不会在未来的某一天被后人扔进文明史的垃 圾堆。

兼听则明。这里只是赖特的一家之言, 一人的憧憬, 一 部分想法。我们需要把古今中外各路神仙对“宜居城市”的

“偏见”综合起来, 结合我们的现实, 形成新的正确与错误 的伦理观。

赖特“未来城市三部曲”第三部的书名就叫《宜居城 市》(The Living City)。“Living” 这个词可以翻译过来的意思 很多, “有生命的”、“活着的”、“有机的”、“(适宜) 居住的” 等等。所以, 我一开始把这本书的书名翻译成“有生命的城 市”, 或 “有机城市”。可是, 我在翻译这本书的过程中, 始 终都在想如何翻译这本书的书名更能准确表达作者的思想, 直到把这本书全部翻译完成, 我还是觉得把“living”翻译 成“(适宜) 居住的”比较贴近赖特书中所追求的那个“有 生命的城市”。“有生命的”或“活着的”、“有机的”城市才 是适宜于我们居住的城市, 换句话说, “宜居城市”是“有 生命的”、“活着的”、“有机的”。如果读者认为这个翻译与 书中内容不符, 应另起一个书名, 请不客赐教。书稿还在建 工出版社加工, 我们还有机会改。 